\title{
EL INELUDIBLE EMPLEO DE LA CIENCIA POLÍTICA Y LA CRIMINOLOGÍA PARA GARANTIZAR LA SEGURIDAD INTEGRAL DE LA POBLACIÓN EN LOS PAÍSES IBEROAMERICANOS
}

\author{
THE INELUDIBLE EMPLOYMENT OF POLITICAL SCIENCE AND \\ CRIMINOLOGY TO GUARANTEE THE INTEGRAL SECURITY OF THE \\ POPULATION IN THE IBEROAMERICAN COUNTRIES
}

\author{
Dr. Dr. Dr. H.C. Gino Ríos Patio \\ Universidad de San Martin de Porres \\ Presidente de la Sociedad Peruana de Criminología \\ ORCID: 0000-0002-0209-2645 \\ Código RENACYT: POO10302 \\ gino_rios@usmp.pe \\ Perú
}

\section{SUMARIO}

- Introducción

- La cuestión criminal en los países iberoamericanos

- El Estado posmoderno y la deslegitimación del ius puniendi

- El poder de criminalización como causa de la criminalidad

- Gobernar a través del crimen

- La desjuridización de la cuestión criminal

- Conclusiones

- Fuentes de información

\section{RESUMEN}

El autor analiza crítica, pero constructivamente, desde la ciencia política, la antropología social, la sociología y la criminología, el problema de la ausencia de seguridad integral en los países iberoamericanos, situación contraria a uno de los dos fines esenciales de todo estado, lo cual se manifiesta en elevados índices de criminalidad y de percepción de inseguridad, debidos a la política imperante de corte neo liberal en lo económico y de expansionismo penal como toda respuesta del Estado, que conlleva sobre criminalización, hiperpunitivismo, populismo punitivo, prisionización $\mathrm{y}$ normalización de la violencia, aspectos todos ellos que configuran una gobernanza a través del crimen, sin vocación política para superar el grave problema social que entraña la cuestión criminal. Concluye en que la política éticamente ejercida y la criminología deben ser empleadas para resolver eficazmente el problema.

\section{ABSTRACT}

The author analyzes critically, but constructively, from political science, social anthropology, sociology and criminology, the problem of the lack of comprehensive security in Ibero-American countries, a situation contrary to one of the two essential purposes of any state, what which is manifested in high crime rates and perception of insecurity, due to the prevailing policy of a neo-liberal court in economic matters and criminal expansionism as any response from the State, which involves criminalization, hyperpunitivism, punitive populism, 
The ineludible employment of political science and criminology to guarantee the integral security of the population in the iberoamerican countries

imprisonment and normalization of violence, all aspects of which shape governance through crime, without a political vocation to overcome the serious social problem involved in the criminal question. It concludes that ethically exercised politics and criminology must be used to effectively solve the problem.

\section{PALABRAS CLAVE}

Política; criminología; criminalidad; seguridad.

\section{KEYWORDS}

Politics; criminology; criminality; security.

\section{INTRODUCCIÓN}

La realidad problemática en cuestión, esto es, la cuestión criminal y la falta de seguridad integral en los países iberoamericanos, es observable en la cotidianidad de la vida social, está registrada en las estadísticas y, asimismo, es analizable en la normatividad y operatividad del sistema de control social formal penal, el cual ha perdido seguridad de respuesta y, además, las drásticas sanciones que aplica son carentes de racionalidad y oportunidades desaprovechadas con relación a la reeducación y resocialización del hombre.

El tema de la seguridad integral es muy importante para investigar en cualquier forma de estado, pues tiene que ver con la vida de las personas; y en la región conformada por los países iberoamericanos es interesante abordarlo científicamente de una manera multidisciplinar y extra penal, aunque por cierto siempre se normativiza y opera penalmente la configuración de dominación social, de ahí que haya que cuestionar también el sistema penal, pero no exclusivamente pues es tan solo una manifestación de estructuras previas; por lo que el tratamiento dado al problema en el presente artículo resulta original.
El objetivo múltiple de la investigación es el de acreditar la necesidad de preocuparse por el trascendental problema descrito; motivar la reflexión y deliberación pública sobre la nocividad social de la política imperante que genera inseguridad y más crímenes y criminales; repensar la inutilidad social de aplicar prima ratio el sistema penal; y recapacitar en la conveniencia común de dar paso a una política de estado que provea condiciones esenciales de seguridad integral y una política criminológica de prevención y control del crimen; con la finalidad de enfocar de manera diferente la comprensión empática de la cuestión criminal y preocuparnos por recuperar el humanismo frente a la actual política que exacerba el individualismo, la insolidaridad y el consumismo.

La investigación arriba a la conclusión principal de que en la actual época de la civilización, caracterizada por el reconocimiento y la consagración política de los derechos humanos; el desarrollo científico y tecnológico; y el progreso económico; es menester que la política estatal de los países iberoamericanos, que son objeto de este análisis, se fundamente en la salvaguarda y el respeto a la dignidad de la persona humana como fin supremo de la sociedad y el estado; y en el indispensable cumplimiento del fin estatal de dotar de seguridad integral a la población y, en esa medida, prevenir y controlar la criminalidad reduciéndolas a niveles tolerables $\mathrm{y}$ compatibles con la vida social, junto con condiciones básicas de bienestar, que constituye el otro fin esencial del estado, para lo cual es inevitable emplear las ciencias sociales, tales como la sociología, la antropología, la política y la criminología, para realizar una auténtica reforma política y diseñar políticas públicas que permitan el logro de los fines para los cuales la sociedad se organizó política y jurídicamente. 
La investigación que se presenta en este artículo se justifica teóricamente porque los gobiernos y los pueblos de los países iberoamericanos han perdido sentido de pertinencia en el empleo de la ciencia política y la criminología, que les impide adoptar una política de estado que permita ejecutar políticas públicas que den seguridad integral, en el sentido liberal del término, y no únicamente medidas administrativas y situacionales de seguridad, que por sí mismas no previenen las causas de la criminalidad ni sirven para reducirla.

La investigación, asimismo, presenta gran utilidad social pues la seguridad integral constituye uno de los dos fines esenciales de todo estado $\mathrm{y}$, por ende, servirá para repensar la forma ineficaz como se está respondiendo al crimen desde el estado, caracterizada por ser reactiva, emotiva y selectiva.

Es de estimar, finalmente, el eminente nivel de impacto regional de una investigación multidisciplinar en un tema tan comprometido con los derechos humanos del infractor y la víctima, así como de los deberes del estado y la sociedad en términos de control social, por lo que el tratamiento de la temática que se expondrá en adelante es trascendente desde una perspectiva política, sociológica, antropológica y criminológica, en la medida que la seguridad integral es un fin estatal por excelencia y la ciencia política y la ciencia criminológica son inexcusables para una mejor organización y desarrollo sociales.

\section{LA CUESTION CRIMINAL EN LOS PAISES IBEROAMERICANOS}

La observación directa de la realidad cotidiana y el consumo de la información

\footnotetext{
${ }^{1}$ Disponible en:

www. latinobarometro.org/latdocs/INFORME_2018

_LATINOBAROMETRO.pdf
}

difundida por los medios de comunicación de masas, permiten enfocar un doloroso aspecto de la realidad nacional de los países iberoamericanos, como es el desarrollo incesante de una política de corte neo liberal que privilegia la libertad económica por encima de las demás libertades humanas, el retraimiento del estado en las políticas sociales y la desregulación económica que genera eventuales desequilibrios entre productores y consumidores, que la denominada mano invisible del mercado no nivela, lo cual genera el enriquecimiento de pocos y el masivo empobrecimiento de muchos, medido por el Informe Latinobarómetro (2018) ${ }^{1}$.

Toda la población, no obstante, es influenciada por el nuevo fin primordial de la vida en la pos modernidad, que es el éxito representado por la posesión de ingentes cantidades de dinero y costosos bienes materiales generados a partir de un consumismo irracional, como consecuencia de un individualismo narcisista exacerbado que rechaza la contribución y solidaridad individual y aprueba la competencia salvaje, la intolerancia y la validación de cualquier medio que permita el logro del nuevo fin entronizado.

R. H. Tawney, citado por Geis, G. (2006:12) escribió:

A los fuertes les prometieron una libertad sin límites para el ejercicio de su fuerza. A los débiles, la esperanza de que también ellos podrían llegar a ser fuertes algún día. Ante los ojos de cada uno de ellos hicieron pender un premio de oro, que no todos podían alcanzar, pero por el que todos debían luchar: la encantadora visión de una infinita ampliación. Aseguraron a los hombres que no había otros fines 
The ineludible employment of political science and criminology to guarantee the integral security of the population in the iberoamerican countries

que los propios, no había otra ley que su deseo, ni otro límite distinto del que consideraban recomendable.

El mismo Geis, G. (2006:11) recoge el concepto de anomia de éxito diseñado por Robert Merton, según el cual todo delito es consecuencia del deseo aprendido de éxito financiero como testimonio de valía personal y que "en los estratos altos surge cuando cada éxito temporal, así como las expectativas aumentadas que los asociados exponen [a las personas con éxito], fomentan unas aspiraciones cada vez más elevadas. La cuestión es que los deseos de esta naturaleza son ilimitados y pueden ser insaciables."

No todos, empero, cuentan con los medios a su alcance ni con las oportunidades que la sociedad y el estado deben crear en condiciones de igualdad para todos, para alcanzar el éxito concebido sobre la base de la absurda idea antes anotada, pues siendo efímera la vida humana y teniendo la persona una naturaleza gregaria, es ilógico e irrazonable pensar en acumular bienes costosos per se, sin ninguna finalidad social ulterior que implique la realización y trascendencia de la persona en los demás y no en sí mismo.

El conflicto surge, entonces, porque la cantidad de recursos disponibles para satisfacer las necesidades humanas, sean materiales o inmateriales, son limitados. La pugna basada en los propios intereses y las particulares aspiraciones, sería normal si tuviera como base una sociedad de iguales y si no se acudiera a la violencia para resolverlo, dando lugar así al crimen.

Esto explica que, al mismo tiempo, dichas fuentes -la observación de la realidad y el consumo informativo- permiten ver el consiguiente incremento de la criminalidad y de la percepción de inseguridad, por ende, la normalización de la violencia; y paralelamente el aumento de la duración de las penas, la sobrepoblación y el hacinamiento carcelario.

Lacera observar, además, que ante este panorama social, lo político no reacciona científicamente sino emocionalmente, a través de una respuesta punitiva, cada vez más bárbara y menos civilizada, lo que nos recuerda que la época medieval no se ha ido, sino que permanece entre nosotros, como apunta Zaffaroni, E. (2011).

La explicación propuesta se completa con el inocultable propósito político de gobernar mediante la utilización de la cuestión criminal perjudicando a los ciudadanos pertenecientes a las clases más desfavorecidas económicamente $\mathrm{y}$, por tanto, más vulnerables a la acción política estatal, porque al carecer de fuente de ingresos o poseer los necesarios para sobrevivir, se les considera no funcionales al sistema económico vigente, que se basa en el consumismo para mantener niveles de producción nunca vistos de bienes desechables en poco tiempo, superfluos y prescindibles, que en nada aprovechan a la persona humana, por el contrario sirven utilitariamente para construir el nuevo modelo de hombre irreflexivo, ahistórico y acrítico.

De esa manera, el arquetipo del hombre posmoderno, individualista no comunitario; instintivo no ensimismado en su futuro trascendente como miembro con sentido de pertenencia e identidad nacional; impulsivo no cauteloso en la construcción de políticas públicas; es construido por el poder planetario del nuevo orden mundial, que apoyado en la globalización y la tecnología de uso masivo, ha inocuizado los estados nacionales, desterrado los valores $\mathrm{y}$ tradiciones propios e impuesto en la realidad nacional de los países iberoamericanos ideas foráneas para las que, en el mejor de los casos, aún falta madurar. 
Ante la descrita situación problemática, que es común a los países iberoamericanos por su mismo origen, tipos de gobierno y cosmovisión cultural ancestral, el artículo que se postula pretende en el período estelar de los derechos humanos y la democracia, precisamente, demostrar la necesidad de adoptar en nuestros países una política de estado que tenga como fin axiológico y teleológico el defender y respetar a la persona humana para garantizar su seguridad integral, lo cual tendrá efectos positivos en la prevención y reducción de la criminalidad a niveles compatibles con la convivencia social.

$\mathrm{Al}$ autor le impele la trascendencia de un tema concreto y dramático, como el de la seguridad integral, que es un fin esencial del estado, el cual solo puede ser científicamente abordado y solucionado con eficacia mediante el empleo de la ciencia política y la criminología, de ahí la elección del problema de investigación para su análisis crítico multidisciplinar, desde la múltiple perspectiva política, sociológica, antropológica y criminológica.

\section{EL ESTADO POSMODERNO Y LA DESLEGITIMACIÓN DEL IUS PUNIENDI}

\section{Desemejanzas en las funciones y fines del estado moderno y posmoderno}

El estado moderno, cualquiera sea su forma, surgió como un tipo de organización jurídica y política holística y autónoma, basada en los principios de solidaridad activa y cooperación fraterna de sus miembros, con el propósito de aunar todos los recursos actuales y potenciales para aspirar al bien común, independientemente de la ideología imperante, en beneficio de la población. Su naturaleza artificial, esto es, de entelequia creada por el hombre y que tiene en sí misma el principio de su acción y su fin; y su esencia de realidad secundaria, no primaria como es el hombre, lo caracteriza como un medio para la realización y trascendencia de la persona humana, cuya defensa y respeto de su dignidad son su finalidad existencial.

En vista del carácter ideal del bien común, que es su fin supremo, el estado asume como fines esenciales la creación de condiciones necesarias para proveer de bienestar general y de seguridad integral a todos sus miembros, conceptos estos que son complementarios e interdependientes. No existe uno sin el otro y el nivel alcanzado por uno condiciona el del otro, en un marco obviamente de igualdad.

El estado moderno, empero, viene experimentando transformaciones que actualmente colisionan con los principios sobre los cuales se originó; que afectan las instituciones económicas, políticas, sociales y culturales; y ponen en cuestión el concepto mismo del estado nación, afectando sus fines primigenios y haciendo suponer eventualmente su decadencia, pérdida de funciones incluida, por causa de la globalización, como anota Chevallier, J. (2012), así como -cabe añadir- del neoliberalismo, fenómenos ambos que han dado lugar a la configuración de un estado vacío de contenido, finalidad y funciones sociales.

El investigador se resiste a creer ello, por el contrario, considera que se trata de la aparición de una nueva forma de estado posmoderno, cuyo funcionamiento efectivo depende, como siempre ha sido en todas las formas de organización jurídico política de la sociedad, de principios, valores y sistemas de creencias propios, razón por la cual constituye actualmente un desafío el hecho de que el estado posmoderno iberoamericano cumpla sus fines originarios, independientemente de los baremos políticos coyunturales, y no se convierta en una simple etiqueta.

Para ello, desde el espacio nacional y regional, habrá que desentrañar las 
The ineludible employment of political science and criminology to guarantee the integral security of the population in the iberoamerican countries

innovaciones institucionales acarreadas por el neoliberalismo, la globalización y la tecnología de uso masivo, adaptarlas a la particular realidad nacional y regional, y orientarlas al servicio de la defensa de la persona humana y el respeto de su dignidad, evitando que su utilización en nuestro contexto regional, en virtud a una asimilación automática o su no uso merced a una impugnación mecánica, se vuelva contraria al humanismo.

Podrán subsistir, de esta manera, los valores con los que nació el estado moderno, como son, el racionalismo, la trascendencia y la sustancia del hombre, evitando ser arrasados por el cálculo de réditos, el utilitarismo, la instrumentalización, la impersonalidad, la neutralidad afectiva, entre otros nuevos estilos contemporáneos que hacen del estado pos moderno una especie de sociedad anónima.

Esta disimilitud entre el estado moderno y el posmoderno, presenta como grave defecto la entronización de un extremado individualismo autorreferencial que ha borrado las fronteras entre lo interior de cada quien y lo externo a cada uno, originando que el hombre pierda el punto de apoyo social para la construcción equilibrada de su yo, resultando un ser desarraigado socialmente y causando el narcicismo, la búsqueda ilimitada de felicidad o placer y la hipertrofia del yo, que deviene en altamente criminógeno.

En este nuevo escenario, el desarraigo social de un hombre exageradamente ególatra, lo hace involucionar hacia lo individual y corroe la identidad y el sentido de pertenencia a una comunidad, dejando desatados los instintos atávicos que crean espacios de violencia estructural, institucional, conductual y discursiva que se constituyen en insufribles episodios cotidianos.

\section{El atributo del estado de castigar}

El poder de criminalización, esto es, de definir cuáles conductas son criminales; de asignar la cualidad de criminal a un ciudadano y rotularlo con la consiguiente estigmatización; y de decidir la ejecución de la pena, tiene naturaleza política y lo ejerce el estado desde el siglo XIII en Occidente, como lo registra Anitua, G. (2015), habiendo sido utilizado como arma política contra adversarios $\mathrm{u}$ opositores a los intereses del régimen de turno, en esa deformación de la noble actividad humana que es la actividad política y de la delicada pero distorsionada tarea de ministrar justicia, acertadamente denominada la politización de la justicia, en los países iberoamericanos.

Ergo, la causa de la criminalidad no está en el individuo o en su entorno social, como se sostenía desde la criminología positivista, sino en el ejercicio perverso del poder político, desviado de su ethos y del telos de la organización jurídico-política de la sociedad, que apunta al respeto, defensa y promoción de la dignidad de la persona humana y sus derechos fundamentales.

Desde el siglo XII hasta antes de la criminología crítica que aparece en el siglo $\mathrm{XX}$, la demonología que sustentó la inquisición y las posteriores escuelas criminológicas positivistas consideraban que las causas de la criminalidad estaban en el interior del individuo o en su entorno social. Desde aquella época, instalados en el paradigma etiológico, se pensaba la cuestión criminal en términos del enfoque positivista criminológico, pretendiendo identificar la causa de la criminalidad en el individuo transgresor, dentro o fuera de él, sea en su biología -anatómica, genética o endocrinológica-, en su psicología o en su entorno social. Por ello, aún se le califica mediática y socialmente como anormal o monstruo, trastornado o desviado. Y claro, tales epítetos se le atribuyen públicamente con carácter previo a su juzgamiento $\mathrm{y}$ 
condena, afectando su derecho inalienable a la presunción de inocencia.

Desde que apareció la criminología crítica cambia el enfoque y se ve el problema de la criminalidad macroscópicamente, vinculándola al poder de criminalización.

A partir de 1970 la criminología crítica postula la teoría según la cual la criminalidad debe ser entendida como una conducta que se les atribuye solo a determinados individuos carentes de poder, sea porque no lo han tenido nunca o sea porque lo han perdido, lo cual destruye, en cualquier caso, el mito del pacto social. De esta manera, el centro de la cuestión criminal se traslada del individuo al poder de criminalización que tiene el estado. Esta nueva concepción criminológica sostenida por Baratta, A. (2002:109), entre otros criminólogos críticos, afirma que "la criminalidad no existe en la naturaleza, sino que es una realidad construida socialmente a través de procesos de definición y de interacción".

Como sostiene Becker, citado por Salo de Carvalho (2014:95), la desviación no es una cualidad del acto o de la persona que lo comete, sino la consecuencia de una etiqueta que se le atribuye satisfactoriamente, de donde resulta que el comportamiento desviado es la conducta etiquetada. De esa manera, aparece la artificialidad del delito y colapsa la perspectiva criminológica positivista, que afirmaba que el delito era neutral y los delincuentes eran anormales. El labeling approach o etiquetamiento fue el puente

2 Políticamente se construyen símbolos para sensibilizar a la población para conducirla y controlarla con la finalidad de conservar el poder. En el ejercicio del ius puniendi estatal, el poder trasmite al derecho penal sus intereses, que son normativizados y operados por el sistema penal a través de sus agencias con determinado sesgo. Así, el simbolismo penal se demuestra en toda su extensión, porque como anota Zavala, L. (2017): tendido por la sociología criminológica para el surgimiento de la criminología crítica, la que incluyó las relaciones de poder en la generación del crimen, toda vez que ciertos grupos o clases detentan la capacidad de elegir las conductas ilícitas y sus responsables.

Así, pues, para la criminología crítica, también denominada politología del delito, la causa de la criminalidad está constituida por la existencia de estructuras económicas, culturales, políticas y sociales desiguales e injustas; y por la discriminación y exclusión social. Esto permite comprender que la cuestión criminal tiene un espacio extra penal y, asimismo, facilita la percepción de un hecho que no es notorio, cual es, que la reacción social genera desviación y no al contrario, pues son las estructuras sociales inicuas, desiguales y excluyentes las que forman personas conflictivas y no al revés.

Se aprecia, desde entonces, que la criminalidad es un problema social que debe merecer la respuesta integral del estado y la sociedad; que su causa última no está en el individuo, como sostenían todas las escuelas criminológicas previas, que eran positivistas por basarse en lo observable, sino en el proceso de criminalización, esto es, en el ejercicio del poder de definición de conductas criminales, de asignación de la condición de criminal y de la ejecución de las penas, todo lo cual configura el ejercicio del poder de castigar del Estado o ius puniendi, que es ineficaz a la luz de los resultados del índice de la criminalidad que habiendo sido simbólico $^{2}$ ha perdido representación para

(...) existe sistémicamente una pretensión política de prohibir sin que, necesariamente, se den los contextos, situaciones y escenarios para que las normas penales cumplan con su verdadera finalidad. Es el caso de las penas en general y de la pena privativa de libertad en particular; de la neo criminalización y la sobre criminalización; de las leyes penales medioambientales; las de punición de la criminalidad organizada; las de delitos 
The ineludible employment of political science and criminology to guarantee the integral security of the population in the iberoamerican countries

devenir en un fetichismo penal ${ }^{3}$. Además, la naturaleza y operatividad del sistema es, como apunta Zaffaroni, E. (1998), ilegítima, ilegal, falsa, alucinante y perversa. En efecto, siendo la legitimidad la expresión de la racionalidad, la representatividad y el consenso, el sistema penal adolece de legitimidad al ser una manifestación del poder de unos sobre otros, motivo por el cual no todos los delitos son perseguidos, procesados ni sancionados ni todos los responsables de los delitos están condenados, por la misma razón que no todos los que están con pena privativa de la libertad a título de condena son responsables, de donde se desprende que a través del sistema penal se activa y opera un poder planificado, aunque no racionalmente, lo que lleva a deducir que el sistema penal carece de coherencia interna pues no existe fundamentación antropológica en su normatividad, pese a la raigambre jus filosófica de todo estado social y democrático de derecho, generalmente recogido y consagrado constitucionalmente; y pese a que un orden

económicos; las de privación de beneficios penitenciarios; las de imprescriptibilidad de algunos delitos. Estas y otras tantas se promulgan en estos tiempos con periodicidad y frecuencia asombrosa para mantener y fomentar la confianza y lealtad en el derecho, para decir que el sistema es invulnerable y predicar la libertad e igualdad en todas sus manifestaciones, como por ejemplo, en la ley y su aplicación. Lo cierto es que constituyen procesos comunicativos de intromisiones meramente simbólicas, por cuanto no sirven para prevenir, controlar ni reducir la criminalidad, pero aparentan proporcionar seguridad y tranquilidad. En todos estos casos, se aprecia una instrumentalización del derecho penal para contraponer una situación real y una situación aparente, el fondo y la forma, lo notorio y lo sabido, lo que se dice querer lograr y lo que se aplica; es decir, hay simbolismo cuando existe engaño e ilusión. ¿Acaso las normas penales están en condiciones de hacer los cambios sociales que se requieren para que la criminalidad disminuya? El derecho penal es una expresión política de poder. Pero no solamente es cuestión de poder e intereses, sino que también comprende el suministro y la protección de símbolos que tienen potencial emotivo jurídico debe ser concordante con el telos del derecho como límite al poder.

Consiguientemente, en opinión del mismo Zaffaroni, E. (1998), que el investigador comparte, el sistema penal no tiene valor de verdad, con lo cual está privado de operatividad social y no logra realizarse en la realidad, por elaborarse además sobre un texto legal justificado mediante la dogmática a la manera de un deber ser que no es y que no llegará nunca a ser por las deficiencias del propio sistema.

Efectivamente, es público y notorio, conforme a la experiencia social, que el sistema penal no es el medio adecuado para la obtención de los fines que se propone alcanzar, como es prevenir y controlar el crimen, limitándose por ello, concretamente, a una adecuación operativa mínima sobre la realidad conforme a la planificación prevista en el deber ser del discurso. Entonces, al no ser el medio adecuado para lograr la prevención y control de la criminalidad y tampoco operar en la sociedad de manera adecuada, resulta

y manipulador, con lo cual el poder político desarrolla la capacidad de generar ficciones y mitos. A tal efecto, despliega todo su arsenal penal simbólico, como leyes que declaran líricamente valores que en la praxis, y por otras vías, el mismo Estado no respeta; leyes de apelación moral, que pretenden infructuosamente crear conciencia a determinadas personas que gozan de posiciones relevantes; leyes que sirven de coartada, leyes de crisis, leyes de contestaciones sustitutas para calmar a la opinión pública; y leyes de compromiso, que pretende satisfacer la necesidad del gobierno de actuar ante la criminalidad aparente.

\footnotetext{
${ }^{3}$ Se conoce como fetichismo a la creencia de que los objetos materiales poseen poderes mágicos o sobrenaturales y que protegen al creyente de las fuerzas malignas. Recurrir al Derecho Penal para ilusionar a los ciudadanos de que es una solución a cualquier problema de conflictividad, violencia y criminalidad, es fetichismo. El Derecho Penal no lo puede todo. Sus escasas posibilidades radican únicamente en castigar.
} 
que es un instrumento coactivo que no es verdadero socialmente, por lo que su existencia es falsa, engañosa e ilusionista, pues se vende como la panacea para resolver todos los problemas sociales, cuando no es así, siendo además perverso al confundir a la población respecto al verdadero ejercicio de poder que oculta.

El mismo Zaffaroni, E. (1998) anota que el sistema penal es ilegal porque solo se ocupa de la legalidad de lo que las agencias penales quieren, operando según las directivas del poder y no de acuerdo con la legalidad, la cual exige que el ejercicio de poder punitivo se realice dentro de los límites previamente establecidos a la tipicidad y punibilidad. Carece, asimismo, de legalidad procesal, pues debe criminalizar a todo aquel que comete un ilícito, lo cual no se da, dejando fuera una gran parte de la realidad, por lo que además de reprimir, configura la realidad como desea, etiquetando y estigmatizando a las personas a las que se dirige, excluyendo la naturalidad y coactando la libertad, reemplazándolas por una sociedad controlada y vigilada in extremis por la autoridad.

Se tiene, entonces, que el sistema penal es selectivo, discriminatorio y reproduce las condiciones de violencia existentes en la sociedad.

La injusta estructura económica, así como la desigualdad y exclusión social, son causas que hacen detonar diversos factores criminógenos de índole biológica, psicológica y sociológica, sin embargo se debe tener en cuenta que el criminal es una persona como cualquier otra que por determinadas carencias individuales $\mathrm{y}$ sociales, materiales e inmateriales, perdió el interés, respeto y sensibilidad hacia los demás, como la propia auto estima, y decidió desviar su comportamiento y utilizar los recursos que posee, de cualquier índole, en la solución de sus conflictos.
Al ser las causas macrológicas, lo razonable es intervenir positivamente en las causas para prevenir y reducir la criminalidad, a través de una política criminológica adecuada y diseñada con base en el conocimiento científico criminológico; no intervenir negativamente en las manifestaciones criminales de dichas causas para castigarlas irrazonablemente, afectando los principios penales liberales, tales como, de legalidad, taxatividad, lesividad, igualdad, humanidad, proporcionalidad, intervención mínima, última ratio, ne bis in ídem, derecho penal de autor, entre otros.

\section{EL PODER DE CRIMINALIZACIÓN COMO CAUSA DE LA CRIMINALIDAD}

\section{La producción de criminalidad por el neoliberalismo}

Desde 1970 un proyecto hegemónico denominado neoliberalismo cambió intensamente a las sociedades contemporáneas occidentales en lo económico, político, social y cultural. Este fenómeno está caracterizado por la promoción del libre mercado; la supresión del gasto público; la búsqueda de saludables índices macroeconómicos; la flexibilidad laboral en el mercado del trabajo; la desregulación de los mercados; y el incentivo a la privatización.

El neoliberalismo ha generado una sociedad indiferente con el prójimo, en la que la desigualdad reemplazó a la igualdad; se eterniza la riqueza para los que detentan el capital, impidiendo el ascenso social de las clases medias y bajas; y expone a la población al empobrecimiento mientras que a reducidos sectores los favorece. De hecho, originó un cambio esencial en el funcionamiento del Estado y en sus principios originarios relacionados con la responsabilidad social. Como diría 
The ineludible employment of political science and criminology to guarantee the integral security of the population in the iberoamerican countries

Waqcuant, L. (2010) el Estado cedió su rol decisorio en el plano económico a la ley de la oferta y la demanda, es decir, a lo que se conoce desde Adam Smith como la mano invisible del mercado.

Esa disminución del tamaño del estado en lo económico, no tiene un correlato en su rol de garante del control penal, por el contrario, en este ámbito amplió y extendió su actividad mediante la puesta en práctica de una política penal caracterizada por el expansionismo, la hiper punibilidad y el populismo punitivo, todo lo cual configura un tipo de gobierno a través del crimen, especializado en desplazar hacia la periferia y los márgenes sociales a los grupos más carenciados, que por esa condición están fuera del mercado, no resultando funcionales al sistema, por lo que la suerte que corren no interesa.

A partir de esta nueva política, el orden se mantiene con la intervención penal, cuanto más adelantada y grave mejor, sin que importe si ese orden es justo, equilibrado e inclusivo, pues la pobreza y la protesta también son criminalizadas. La estrategia consiste en vender la idea de orden y seguridad para que todos asimilen la idea de la necesidad de un control penal severo y violento. A esto se le conoce como populismo punitivo.

El neoliberalismo, de esa manera, reduce el orden social a una ecuación simplista, que supone que a más criminalidad se debe impartir penas más graves, lo cual a su vez implica más leyes penales, más policías, más fiscales, más jueces, más agentes penitenciarios, más prisión preventiva, más violencia y un largo etcétera del mismo jaez. Es decir, el expansionismo penal en su máxima expresión.

Al exacerbar, en suma, la libertad económica por encima de las demás libertades, el neoliberalismo desvalora el derecho penal, la democracia y la seguridad integral. Ésta, que es uno de los dos fines esenciales de todo estado, es definida desde una perspectiva liberal, como el goce pleno $\mathrm{y}$ el real ejercicio de todos los derechos fundamentales y libertades humanas, que hace que el hombre se sienta seguro cuando tiene qué comer nutritivamente, dónde vivir dignamente, trabajo, dónde curar su salud, dónde educarse, tranquilidad, previsión social adecuada, etc.

El paradigma neoliberal, además, diseña el control penal de manera selectiva $y$ discriminatoria, al perseguir y castigar a la criminalidad callejera, dejando de lado la persecución y sanción a la criminalidad económica, política, empresarial, medio ambiental y a toda aquella en la que el infractor mantenga una cuota notable de poder.

\section{La normalización de la violencia}

El neoliberalismo ha logrado, de esta manera, asentar en la sociedad, con ayuda de los mass media, la relación crimenpobreza, así como ha creado la duda entre inseguridad y sensación de inseguridad.

Los medios de comunicación masiva, en efecto, producen y venden noticias $\mathrm{y}$ contenido informativo trastocando la realidad con el único objetivo de defender sus intereses, los cuales en plena época neoliberal no son otros que los de ganar más dinero con lo que hacen y, entonces, el sensacionalismo, el efectismo y la deformación de la realidad son moneda corriente.

Y claro, la violencia y la criminalidad son mercancías noticiosas que causan adicción en la sociedad. Por eso se habla de una mediatización de la violencia y una naturalización del crimen. La población que consume la noticia, que es repetida hasta tres veces sucesivas y tres veces al día, todos los días de la semana; se habitúa de tal manera a consumirla que exhibe 
manifiestamente un hábito de consumo nocivo, pues se trata de la asimilación mental de violencia, intimidación y crimen, cuya sobre exposición causa un gran pánico moral y origina un círculo vicioso de información y comportamientos maníacos que se traducen en inseguridad y, al mismo tiempo, en el clamor popular de más penas, es decir, más violencia estatal.

En tal escenario, los medios de comunicación masiva contribuyen a generar el consenso respecto de la criminalidad y la inseguridad, formando paradigmas negativos sobre la identidad del criminal -siempre o casi siempre el marginal- y de la víctima -también perteneciente al grupo social carenciado, de clase media $\mathrm{u}$ otros vulnerables (criminalidad intra clase), pues los ciudadanos poderosos económicamente se proveen su propia seguridad personal y ambiental- generando la falsa creencia de que el reclamo de seguridad ciudadana y de justicia, y la consiguiente penalidad rigurosa, extinguirá la delincuencia, lo que la experiencia demuestra que es falaz.

En ese sentido, los mass media masivos junto con la clase política- son serviciales con la criminalización de los sectores marginales, creando en asociación indisoluble con el poder los crímenes y los criminales hacia los que se dirige el neo punitivismo del neoliberalismo.

\section{El negocio de la criminalidad}

El neoliberalismo influye poderosamente en el sistema penal y de política penal. En principio, el ius puniendi, como sostiene Waqcuant, L. (2010) se utiliza como un instrumento que impide ver los problemas sociales que el Estado no resuelve desde sus raíces y el presidio se emplea como un depósito de seres humanos puestos allí por la agencia penal judicial al ser excluidos de la sociedad de mercado. Cabe recordar que esas causas que la criminología crítica sitúa en una injusta y desigual estructura económica y en un sistema social no inclusivo y discriminatorio, se exacerban con el neoliberalismo y tienen efectos devastadores en los factores biológicos, psicológicos, sociológicos y culturales que inciden sobre el ser humano y delinean su comportamiento.

Por eso, Gargarella, R. (2016) señala que cuando la ley es creada sólo por unos pocos, tienden a dañar a parte de la comunidad y ser indebidamente parciales.

En ese sentido, el crimen es un negocio, una industria, un fenómeno que genera dinero y ganancias, rubro en el que se alinean también las empresas de seguridad y los que actúan en el sistema penal, lo que incluye a abogados de la especialidad y operadores en general.

Pero sobre todo es una estrategia y un instrumento de gobernanza. En efecto, a través del crimen se gobierna a los ciudadanos, ofreciendo en las campañas electorales acabar con el crimen o presentando proyectos de ley -generalmente copiados de otras realidades y tiempos pasados- para aumentar las penas a límites y modalidades de aplicación inimaginables en una civilización, como el retorno a la pena de muerte, la privación de los derechos civiles y políticos, denominada muerte civil, y hasta el intento de instaurar la castración química para violadores sexuales. La lista de evidencias sobre la gobernanza a través del crimen es interminable, siguen el uso desmedido y arbitrario de la prisión preventiva que la convierte en una acción controlada; el legislar en materia penal mediante decretos legislativos; el excesivo adelantamiento de la barrera criminal a niveles de sospecha o estados situacionales, ya no de actos conductuales; el impedimento de la rehabilitación del condenado a condición del pago de la reparación civil, entre otros despropósitos penales. 
The ineludible employment of political science and criminology to guarantee the integral security of the population in the iberoamerican countries

Así, el uso del ius puniendi como prima ratio, no como última ratio; el quebrantamiento de los principios penales liberales, como el de legalidad, taxatividad, proporcionalidad, no trascendencia de las penas, humanismo, garantismo procesal, derecho penal de acto y no de autor, entre otros; la preeminencia del derecho penal del enemigo; el simbolismo penal; la sobre criminalización; el hiper punitivismo; el populismo punitivo; la selectividad $\mathrm{y}$ discriminación del sistema penal; la exacerbación del pánico moral; la normalización del crimen; la mediatización de la violencia; y la banalización de la cuestión criminal, implican una gobernanza a través del crimen, que constituye una pésima doctrina y peor acción política, penal y social, llamada derecho penal del enemigo, que es considerado no persona por estimarlo peligroso y, por ende, sin derecho a invocar principios y acogerse a garantías constitucionales.

Es decir, el Estado persigue al infractor en la idea -deliberada, no inocente- de que es el origen del mal, la fuente del crimen, pero se ocupa únicamente de perseguir, procesar y condenar a los ciudadanos que incurren en lo que se conoce como criminalidad callejera, no así a las otras manifestaciones de criminalidad que son más lesivas porque afectan bienes jurídicos de toda la sociedad peruana, como la criminalidad de cuello blanco, la criminalidad medio ambiental, la criminalidad económica y la del poder político vinculada a los crímenes de lesa humanidad.

En síntesis, solo los ciudadanos pertenecientes a las clases más vulnerables, carenciadas y marginales conforman la carne de presidio y eventualmente algunas personas que pierden poder, sobre todo político, lo cual confirma que el ejercicio del ius puniendi estatal es político, desde que el estado en el siglo XIII confiscó la administración monopólica de justicia.

\section{GOBERNAR A TRAVÉS DEL CRIMEN}

\section{El bagaje del expansionismo penal}

El término gobernar a través del crimen es relativamente nuevo si consideramos su empleo por Simon, J. (2011) en el título de su obra Gobernar a través del delito. Sin embargo, es posible aseverar que lo que Simon pretende dar a entender con el sugestivo título tiene antigua data. En efecto, el poder siempre ha exhibido habilidad política para emplear el ius puniendi en la consecución de sus fines. No solo el sistema penal ha sido servicial en estos empeños, también lo ha sido la criminología pre científica, desde la fisionomía hasta la demonología; y la criminología científica, desde el positivismo hasta las escuelas sociológicas previas al labelling approach.

Zaffaroni, E. (2011) lo ilustra irónicamente atribuyendo a la criminología el rol de celestina del derecho penal, por servirle de discurso racionalizador y legitimador (encubridor). Una explicación para tan nefasto empleo de dos ciencias sociales, radicaría en la vocación hegemónica del poder y comprometería la ética del gobernante, el científico social y la población, lo cual dice poco de las virtudes de la democracia en estas circunstancias. Ocurre que el poder siempre necesita de enemigos y de emergencias para reforzar la idea de la necesidad de su existencia y mantenerse vigente. $\mathrm{Si}$ no los tiene, entonces los crea.

El poder siempre ha esgrimido la supuesta razón de estado para opacar al estado de la razón, basándose en el magnífico pretexto de la inseguridad y la ingobernabilidad para hacer uso de medidas penales que avergüenzan al derecho. Hoy, que se ha impuesto a nivel global el neoliberalismo escoltado por la globalización y la 
tecnología de uso masivo, el avance de estas políticas de gobernanza a través del delito es un recurso corriente cuyas expresiones reciben nombres exóticos, como por ejemplo el derecho penal del enemigo, distinto en esencia al derecho penal del ciudadano, lo que ha sido siempre una constante histórica.

Es curioso e insólito en una época de universalización y constitucionalización de los derechos humanos y democracia, haya abusos y autoritarismo en los regímenes políticos, los que originan malestar social, económico y político, para cuyo control los gobiernos aplican la receta neoliberal de contenido penal, consistente en expansionismo penal, sobre criminalización, hiper punitivismo, populismo punitivo, fervor punitivo, mediatización de la violencia, exacerbación del pánico moral, entre otros, mientras se levantan más cárceles que escuelas, hospitales o espacios de solaz para la comunidad. Todo es privado, hasta las cárceles, lo que permite suponer fácilmente que el estado a través de las agencias penales tendrá que ocuparse de enviar una cantidad mensual de personas al presidio y que las penas sean de larga duración para que el inversionista pueda tener réditos, como en todo negocio. Si, contrariamente, se tratase de cárceles públicas, el envío de ciudadanos mantiene un nivel considerable en cuanto a cantidad, para sobre poblarlas, aun cuando se construyan más, con lo cual el fin resocializador y reeducador se tornan imposibles y el círculo vicioso de la criminalidad continúa vigente con altas tasas de reingreso al penal de ciudadanos convertidos en criminales reincidentes y habituales.

En el esquema neoliberal, la acción estatal se contrae y desatiende los servicios públicos que permiten velar por la vigencia de los derechos humanos. Es una verdadera paradoja de la civilización, pues se advierte barbarie punitiva, lo que nos retrotrae al
Antiguo Régimen, en el que el delito era lo que el príncipe decía que era (hoy el Congreso de la República delega comúnmente al Poder Ejecutivo facultades para legislar en materia penal, con lo que el principio de reserva de ley penal languidece) y la pena cuanto más cruel mejor, aun cuando técnicamente ya no son corporales.

\section{La decadencia del sistema penal}

El sistema penal, conformado por la normatividad, la doctrina y las agencias penales, está en declive. Nació para ser un control de la arbitrariedad del poder, un límite frente a los abusos del poder, en un escenario en que el estado monopoliza la administración de justicia penal, es decir, la gestión del conflicto, la regulación de la violencia y la gerencia del orden público, jurídico y social. Sin embargo, es la expresión más desproporcionada de fuerza; más grave y desatada de violencia; y más inicua de discriminación y desigualdad ante la ley.

El castigo penal a los pobres se ha mundializado por efecto del neoliberalismo, que preconiza la responsabilidad individual, olvidando que el comportamiento humano tiene raíces profundas y de múltiples y variadas aristas. El ser humano es la simbiosis de su biología, psicología, historia, etnología, cultura, política, economía y sociología, por lo que la responsabilidad social es innegable en su actividad individual. Su conducta es determinada y determinable. Por eso el poder debe servir al hombre y no servirse de él.

¿Por qué los niveles de criminalidad se incrementan incesantemente? ¿Por qué las tasas de criminalidad crecen y la población penitenciaria aumenta pese a la gran inversión en seguridad pública y privada? El autor es de opinión que la pobreza iberoamericana no se debe a una escasez de 
The ineludible employment of political science and criminology to guarantee the integral security of the population in the iberoamerican countries

recursos naturales, pues es una región de ingentes materias primas estratégicas, generación de energía barata, potencial para la producción agropecuaria; ni a las guerras, pues no ha sido lugar de conflagraciones bélicas extendidas espacialmente ni de largos períodos de tiempo como en Europa. Se debe al deterioro social que viene por el incremento de las polarizaciones sociales, según Kliksberg, B. (2002:87, 88):

Por ser el continente más desigual de todo el planeta, en donde el $10 \%$ más rico de la población tiene 84 veces el ingreso del $10 \%$ más pobre, y la región presenta el peor coeficiente de desigualdad en la distribución de los ingresos. Asimismo, registra pronunciadas desigualdades en el acceso a la tierra y otros bienes de capital, en la posibilidad de obtener créditos, y en el campo educativo.

Tenemos así que la injusta distribución de la riqueza facilitada por un sistema económico neoliberal y político de falsa democracia, genera desigualdad social y agrava las polarizaciones sociales, configurando un escenario de graves tensiones sociales. Si frente a ello, el estado opta por retirarse de la economía dejándola en manos privadas, pierde su carácter regulador y su responsabilidad social, originando una masa de excluidos cuyo disciplinamiento social se hace a través del expansionismo penal y el hiper punitivismo.

\section{LA DESJURIDIZACIÓN DE LA CUESTIÓN CRIMINAL}

\section{EI crimen no nace en la ley penal}

El crimen no es otra cosa que un conflicto violento intersubjetivo que ocasiona beneficio a unos y daño a otros. Como conflicto, su base es la discrepancia y divergencia en cuanto a los intereses y aspiraciones que todas las personas tienen para aspirar a la satisfacción de sus necesidades y que pretenden imponer sobre los demás porque no están formadas en la capacidad de resolver los conflictos pacíficamente, dialogando, escuchando, comprendiendo, tolerando y sumando esfuerzos; y esencialmente porque no hay una relación social de alteridad, esto es, de reconocimiento de que se trata de personas iguales en dignidad y derechos, sino de ajenidad. Es penoso decirlo pero en la región iberoamericana los estados independientes se han formado sobre sociedades de desiguales y esta es una de las deudas políticas más importantes, que impide precisamente construir una democracia inclusiva y material.

A lo anterior se suma el hecho de que el propio estado no gestiona el conflicto ni lo dirime en justicia, peor aún, al decidir sobre un crimen (conflicto violento) castiga gravemente al infractor no porque ha ocasionado un daño a la víctima sino porque ha quebrantado la ley, sin que le importe reeducar, resocializar ni rehabilitar al infractor; y re victimiza durante el proceso a la víctima sin que importe su reivindicación, desagravio y reparación, lo que está demostrado con el hecho público y notorio de que la reparación civil no se paga, entre otras razones, fundamentalmente porque al ser los infractores ciudadanos marginales $y$ carenciales, no tienen recursos ni bienes registrados para cumplir con dicha obligación. Por cierto, el estado no piensa en que, en tales casos, él tenga que asumir el pago de la reparación civil, como ocurre en España y otros países europeos, como reconocimiento de la co responsabilidad existente.

Como se puede advertir, el crimen nace en la realidad, en el seno social, no en la ley penal, por lo que es un problema comunitario, de todos, no solo del infractor y la víctima, que obviamente merece una 
respuesta comunitaria, no únicamente del estado, que ha demostrado, en Iberoamérica, reaccionar y no prevenir; violentar a los involucrados y la sociedad con pánico moral y sensación de inseguridad, en lugar de infundir tranquilidad; y castigar draconianamente en vez de comprender e intervenir positivamente en el infractor y la víctima, para propiciar cambios personales y no enraizarlos en la criminalidad y desamparo moral.

Por ello, la respuesta no debe ser penal, no solo porque el sistema penal tiene déficit de oportunidad, ya que siempre llega tarde; déficit de comunidad porque no soluciona el conflicto subyacente, el cual se sedimenta en la base de la sociedad; y déficit social, por cuanto la sociedad no participa en la elaboración de las leyes penales, ni directamente ni por medio de sus representantes al Congreso Nacional, pues éste delega funciones legislativas al Poder Ejecutivo para tal propósito; sino porque el crimen no nace en su ámbito, sólo está diseñado para castigar, lo cual ayuda a mantener el poder de la autoridad.

\section{Una reforma política pendiente}

En ese escenario, que es común en la región en cuanto al origen, respuesta y proyección de la cuestión criminal, según la perspectiva criminológica contemporánea, la reforma política que está pendiente en Iberoamérica es la que concierne al estado y la misma sociedad en su conjunto, por ende, a cada uno individualmente, de elegir muy bien a los representantes políticos, controlar mejor sus acciones políticas de representación y participar pro activamente en el esfuerzo de cumplir el fin estatal de proveer seguridad integral, que no es solo lo que se conoce como seguridad ciudadana, sino el pleno goce y ejercicio de todos los derechos fundamentales, civiles y políticos, económicos, sociales y culturales.
Tomando conciencia de ello y actuando en consecuencia, este curso de acción permitirá amortiguar la política económica neoliberal y filtrar sus medidas para que no se afecte la dignidad y derechos fundamentales de las personas, así como los ciudadanos podrán identificar la gobernanza a través del crimen de que son objeto y desterrar todas sus manifestaciones que tienen que ver con la cuestión criminal y que se han mencionado a lo largo de este artículo.

Las ciencias sociales, que tienen al ser humano como centro de su estudio y como finalidad prioritaria mejorar su existencia, requieren ser convocadas para esta cruzada regional en pro de la purificación del estado moderno, en beneficio del hombre, para mantener su esencia social, naturaleza racional y trascendencia fructífera, en un ámbito que como el de la seguridad, se juega el futuro de su existencia, pues en materia de seguridad integral, la única verdad está en la realidad y la realidad en materia de cuestión criminal son los muertos, no solo los que mueren por acción de la criminalidad callejera y la de cuello blanco, sino fundamentalmente aquellos cuya vida se extingue por la inacción social de un estado de economía neoliberal, ausente y distante de su responsabilidad social, que lamentablemente son muchos más, lo que equivale a un genuino genocidio por goteo, como lo conceptúa Zaffaroni, E. (2011).

\section{CONCLUSIONES}

Es innegable el infausto influjo del neoliberalismo en la configuración de órdenes económicos, culturales, políticos y sociales excluyentes de los ciudadanos más vulnerables, marginales y carenciados. Según el Informe 2018 de la Corporación 
The ineludible employment of political science and criminology to guarantee the integral security of the population in the iberoamerican countries

Latinobarómetro (pp.6-7) ${ }^{4}$ la relación existente entre los problemas económicos (desempleo, economía, pobreza, alimentación y bajos salarios) y la delincuencia en los países de Iberoamérica, se registra en los dos primeros lugares con índices elevados a nivel nacional (35/19), local (20/24) y familiar (48/9), respectivamente.

El creciente nivel de descontento con el sistema democrático de los países de Iberoamérica, registra un $79 \%$ de personas que señalan que se gobierna para unos cuantos grupos poderosos en su propio beneficio, lo cual es un claro indicador del malestar de la población y las críticas al sistema político en el tema de la percepción de distribución de la riqueza, que ha descendido al 16\% en el año 2018.

Esta situación explica por qué desde el poder se ejerce control y dominación mediante el sistema penal selectivamente contra los ciudadanos marginales y carenciados. La respuesta probable tiene que ver con la contención violenta de la protesta proveniente de la pobreza. Una mirada contra fáctica nos permite vislumbrar que si se gobernara en bien del pueblo, la conflictividad, violencia y criminalidad, que se da a nivel estructural, institucional, conductual y discursivo, se reducirían ostensiblemente.

En la página 46 del citado Informe se lee: "Somos la región del mundo más desconfiada de la tierra y por segundo año consecutivo tenemos mínimo histórico de confianza interpersonal". En promedio, existe tan solo un $14 \%$ de confianza interpersonal en los habitantes de Iberoamérica. Respecto a las instituciones, en lo que concierne al Poder Judicial, se tiene que desde el año 2014 en que alcanzó

\footnotetext{
${ }^{4}$ Disponible en:

www.latinobarometro.org/latdocs/INFORME_ 2018 _LATINOBAROMETRO.pdf
}

$30 \%$ ha disminuido seis puntos porcentuales llegando a 24\% en el 2018. Los países que menos confían son, El Salvador $14 \%$, Nicaragua $15 \%$ y Perú $16 \%$, le sigue Venezuela con $18 \%$, de acuerdo con la información de la página 50 del Informe en mención.

En un escenario como el descrito a partir de las cifras precedentes, es lógico que la violencia se haya incrementado. Así lo indica la página 57 del Informe tantas veces mencionado: "La más dañina de todas es la de las calles que alcanza el 35\%. En segundo lugar, se ubica la violencia contra las mujeres con el $26 \%$, en último lugar la violencia de estado con el $8 \%$ ".

Esta explosiva combinación de mala e injusta economía exacerbada por el neoliberalismo, violencia, desconfianza interpersonal e institucional y descontento con el sistema democrático, constituyen las causas de la criminalidad en la región, cuyos países pueden ser considerados como una unidad de análisis criminológico por sus semejanzas de origen, políticas, culturales, sociales y económicas, las cuales inciden en los factores personales para que surja el comportamiento criminal.

Una práctica estatal y social en Iberoamérica es que existe otro responsable de todo lo malo que ocurre en la sociedad. Ese es el ciudadano que pertenece a las poblaciones marginales, que para el estado es de donde proviene la inseguridad y la violencia; y hay que separarlo porque además es desigual, nimio y sacrificable. Tal postura, carente de ética, no sirve para lograr una cohesión social y, además, resulta una palabra incumplida, pues la mano dura no reduce la criminalidad, como el poder afirma. En este estado de cosas, el sistema no castiga a la persona porque es criminal, sino que, al revés, es criminal 
porque se le castiga, lo cual contradice el deber ser de la política y el ethos del poder. La seguridad integral exige que la sociedad y el estado sean empáticos con la cuestión criminal. El problema social de la seguridad es un tema frágil y trascendente para la política y la población de un estado. La política como ciencia, doctrina y acción tiene como fin guiar el ejercicio del poder estatal para aspirar al bien común y lograr el bienestar general y la seguridad integral; el gobierno de los pueblos iberoamericanos mediante el crimen significa una pérdida de democracia y privarlos del ideal político republicano, participativo, representativo y deliberativo, lo cual imposibilita fundar una tendencia de eficacia social sin autoritarismo ni demagogia.

Ante este panorama, es indispensable concienciar a la sociedad acerca del nocivo papel que cumplen en el sistema penal las desigualdades estructurales económicas, sociales y culturales, que como se ha visto en el presente artículo no ofrecen seguridad integral a la población, por lo que resulta urgente centrar los recursos en equilibrar e incluir y no en reprimir y excluir, pues esta política penal ha agravado la criminalidad.

Es imprescindible, asimismo, introducir el tema de la cuestión criminal en la discusión política nacional y defender científicamente -desde la criminología- su prevención, mediante argumentos racionales y científicos que proporciona esta disciplina, a fin de convencer de la necesidad de abordar el problema de fondo extra penalmente, deteniendo la hiperinflación penal existente, que conlleva la construcción de más cárceles y la necesidad de más agentes del sistema penal (policías, fiscales, jueces, agentes penitenciarios) y la afectación de las garantías penales.

Para lograr el estado de cosas antes explicado, el debido empleo de la ciencia política y la ciencia criminológica deben revalorarse como los instrumentos fundamentales para concebir que la seguridad integral como fin esencial del estado no se limita a la seguridad ciudadana, sino que implica el goce y ejercicio de los derechos civiles y políticos, económicos, sociales y culturales; y para proporcionar la información veraz y confiable acerca de la cuestión criminal, que comprende el crimen, el criminal, la víctima y el control social, en términos de la causalidad de los distintos tipos de crímenes, con la que se diseñe una política criminológica de prevención y reducción de la criminalidad, así como de reconstrucción del control social formal, para que sea más horizontal con intervenciones positivas en las personas $\mathrm{y}$ menos vertical y violento, con consecuencias etiquetadoras y estigmatizadoras en los ciudadanos. Los pueblos de los países iberoamericanos lo merecen.

\section{FUENTES DE INFORMACIÓN}

\section{Fuentes bibliográficas}

Anitua, G. (2015). "Historias de los pensamientos criminológicos". Ediciones Didot Buenos Aires, Argentina.

Baratta, A. (2002) "Criminología crítica y crítica del derecho penal. Introducción a la Sociología jurídico-penal" Siglo Veintiuno Editores. Argentina.

Chevallier, J. (2012) "El estado pos moderno" Traducción de Oswaldo Pérez Orozco. Universidad Externado de Colombia. Bogotá.

Gargarella, R. (2016) “Castigar al prójimo. Por una refundación democrática del derecho penal". $1^{\text {a }}$. Edición. Siglo Veintiuno Editores. Buenos Aires.

Simon, J. (2011) "Gobernar a través del delito". Traducción de Victoria de los 
The ineludible employment of political science and criminology to guarantee the integral security of the population in the iberoamerican countries

Angeles Boschirali. Editorial Gedida. Barcelona, España.

Wacquant, L. (2010) "Castigar a los pobres. El gobierno Neoliberal de la inseguridad Social" Editorial Gedisa. Barcelona.

Zaffaroni, R. (1998) "En busca de las penas perdidas. Deslegitimación $y$ dogmática penal" Segunda reimpresión. Editorial EDIAR. Buenos Aires.

Zaffaroni, R. (2011) "La palabra de los muertos. Conferencias de criminología cautelar". Editorial EDIAR. Buenos Aires.

\section{Fuentes hemerográficas}

Salo de Carvalho (2014) "Criminología Crítica: Dimensiones, Significados y Perspectivas Actuales". En Revista de Derechos Humanos y Estudios Sociales. Año VI, (Número 11). Enero-Junio 2014. Traducción al español de Lara Oleques de Almeida. Universidad Autónoma de San Luis Potosí. México.

\section{Fuentes electrónicas}

Corporación Latinobarómetro (2018) “Informe 2018" Banco de Datos en línea. Recuperado de www.latinobarometro.org/latdocs/INFOR ME_2018_LATINOBAROMETRO.pdf

Geis, Gilbert "El delito de cuello blanco como concepto analítico e ideológico. Recuperado de https://dialnet.unirioja.es/servlet/articulo?c odigo $=2250203$

Kliksberg, Bernardo (2002) "El crecimiento de la criminalidad en América Latina: un tema urgente". Recuperado de https://www.redalyc.org/html/904/9042020 $1 /$
Zavala Van Oordt, Lizet (2017) "El derecho penal simbólico y la ineficacia del estado de emergencia constitucional para combatir la criminalidad". Recuperado de https://dialnet.unirioja.es/servlet/articulo?c odigo $=6058757$ 